\title{
Especificidades sobre processo de luto frente ao suicídio
}

\author{
Karina Okajima Fukumitsu \\ Maria Júlia Kovács \\ Universidade de São Paulo \\ São Paulo, SP, Brasil
}

\begin{abstract}
Resumo
O suicídio de um ente querido pode desencadear nas pessoas diversas reações. No presente artigo apresentam-se as especificidades para diferenciar o processo de luto após o suicídio dos demais lutos, causados por outros tipos de morte. O artigo tem o objetivo de refletir sobre o processo de luto pelo suicídio por meio da compreensão do luto de nove filhos de pessoas que consumaram o suicídio. Foram extraídas 14 unidades de significados a partir do método fenomenológico e compreendidas pela perspectiva da abordagem da Gestalt-terapia. Os depoimentos dos colaboradores, apontam que, ao enfrentar a morte, o filho pode experienciar o sofrimento com sentimentos de culpa, raiva, sensações de desamparo, abandono, rejeição, solidão, além da fragmentação de tudo o que era conhecido.
\end{abstract}

Palavras-chave: Suicídio; Prevenção do suicídio; Luto (estado emocional).

\section{Specificities about the grieving process forward to suicide}

\begin{abstract}
The suicide of a loved one can trigger different reactions in people. In the current article which intends to be a research report, the specificities are presented to differentiate the grieving process after a suicide of others grief, caused by other types of death. The article has a purpose of reflecting the process of grieving through the understanding of the nine children - sons and daughters of parents of people who consummated suicide. The results of the research from 14 units of meaning were extracted according to the phenomenological method and understood by the perspective of Gestalt therapy approach, this article has the purpose of reflection about the grieving process of suicide, show that when facing death, the child may live experience whose suffering causes guilt, anger, feelings of helplessness, abandonment, rejection, loneliness and fragmentation of all that was known.
\end{abstract}

Keywords: Suicide; Suicide Prevention; Grief.

\section{Especificidades sobre el proceso de duelo hacia adelante al suicidio}

\section{Resumen}

El suicidio de un ser querido puede provocar en las personas diferentes reacciones. En este artículo, que pretende ser un informe de investigación, se presentan las especificidades para diferenciar el proceso de duelo tras el suicidio de los seres queridos, causado por otros tipos de muerte. En este artículo, pretende ser un informe de investigación, se presentan el proceso de duelo tras el suicidio por medio de la comprensión del luto de nueve hijos de personas que consumaron el suicidio. Los resultados de la investigación, muestran 14 unidades de significado fueron extraídos según el método fenomenológico y entendidos desde la perspectiva del enfoque de la terapia Gestalt, cuando se enfrenta a la muerte, el niño puede tener - vivir experiencias cuyo sufrimiento provoca culpa, ira, sentimiento de desamparo, abandono, rechazo, soledad y la fragmentación de todo lo conocido.

Palabras clave: Suicidio; Prevención del suicidio; Duelo. 
O aumento desenfreado das taxas de suicídios a cada ano em todo o mundo é alarmante. Segundo Botega, Werlang, Cais e Macedo (2006, p. 214), “O suicídio não é tão somente uma tragédia no âmbito pessoal; ele também representa um sério problema de saúde pública". De acordo com os dados do "Mapa da Violência 2014 - Os Jovens do Brasil", do sociólogo Julio Jacobo Waiselfisz, da Faculdade LatinoAmericana de Ciências Sociais (FLACSO), entre 1980 e 2012, as taxas de suicídio no Brasil cresceram 62,5\%, tonando-se a terceira causa de morte no país, depois de acidentes de trânsito e homicídios.

Trata-se de pesquisa qualitativa, baseada no modelo fenomenológico proposto por Edmund Husserl e adaptado por Clark Moustakas (1994), que foi utilizado para as análises dos depoimentos de 9 (nove) colaboradores, tendo como fundamentação a Gestalt-terapia. Busca-se também a discussão sobre o processo de luto por suicídio de maneira mais ampla, não só com filhos de pais que consumaram suicídio, para se compreender o processo de luto de pessoas impactadas pelo suicídio, sem especificação de grau de parentesco. Por ser uma morte violenta, repentina e que pode provocar culpa e autoacusação é demandada muita energia psíquica para a elaboração do luto, chegando-se em algumas obras denominar o enlutado como sobrevivente e como foi considerado no presente artigo.

Pretendemos destacar as especificidades do processo do luto no caso de suicídio cujo caráter é a de ser uma morte repentina, violenta por se tratar de um ato estigmatizado e deliberado. Por esse motivo, além de apresentar os resultados da pesquisa, complementamos com a revisão de literatura nos bancos de dados PubMed, PsycINFO e SveMed+ no período entre 2010 e 2014 com os descritores "suicídio e luto de pais"; "suicídio e luto de filhos"; "suicídio e luto da família"; "suicídio e luto" e "postvention". No banco de dados PubMed, PsycINFO não se encontrou nenhum artigo relacionado com os descritores "suicídio e luto de pais"; "suicídio e luto de filhos"; "suicídio e luto da família"; "suicídio e luto". Já para o descritor "postvention" foram encontrados em PubMed 93 artigos; PsycINFO 2 livros, 2 artigos e 1 relatório da SveMed+ com 2 artigos. As autoras fundamentaram a compreensão do suicídio nos seguintes estudos: Bertolote (2012), Botega et al. (2006), Cassorla (1991), Krüger e Werlang (2010), Jamison (2010), Alvarez (1999) e Shneidman $(1973,1985,1993)$ e luto por suicídio nos seguintes estudos: Franco (2002, 2010), Franco e Polido (2014), Kovács (1992, 2003, 2007), Fukumitsu (2012, 2013), Parkes (1998), Fox e Roldan (2009), Shneidman (1996, 2001) e Clark (2001, 2007).
Posvenção é um termo ainda pouco conhecido em nosso meio. Cândido (2011), introduz o tema a partir da obra de Edwin Shneidman (1985, 1993, 1996, 2001). A posvenção se refere à prevenção, ao luto e às atividades após a perda por suicídio. Conforme Flexhaug e Yazganouglu (2008, p. 20), "posvenção" indica as atividades realizadas para atenuar o abalo da perda por suicídio e possibilita também a prevenção do sofrimento das próximas gerações. Segundo os autores "A estimativa mais comum revela que existem seis sobreviventes para cada morte por suicídio" (p. 18).

O comportamento suicida abrange o espectro individual, social, cultural, histórico de cada época. No Brasil são 32 casos diários de suicídio, ou seja, uma pessoa tira sua própria vida a cada 45 minutos e se há uma morte que acontece por suicídio, outras vidas são impactadas pelo ato de a pessoa se autoaniquilar.

O luto pelo suicídio abarca várias dimensões. Entende-se que da mesma maneira que não se pode reduzir o comportamento suicida a explicações simplistas, o processo de luto não deve apresentar também uma única compreensão. Se não é justo reduzir suicídio do ente amado com explicações reducionistas, com o enlutado não seria diferente. A pessoa que sofre o impacto da morte do suicídio não pode ser rotulada como a vítima ou "a coitada".

O modo de lidar com o fato depende do auto e do heterossuporte do enlutado, ou seja, dos recursos internos e das inúmeras inter-relações e ajustamentos criativos, que ele possa realizar conforme a interação com o meio ambiente. Para Kovács (2007), há fatores que podem influenciar o processo de luto: (a) a relação com a pessoa perdida; (b) natureza da ligação: (intensidade, segurança, ambivalência ou conflitos); (c) forma da morte: repentina e violenta; (d) antecedentes históricos e (e) variáveis de personalidade e sociais. Segundo estudos recentes, o luto é um processo dinâmico, varia de pessoa para pessoa e suscita sensações diversas, como frustração, dor, culpa, dificuldade de encontrar sentido nas coisas, choque, raiva, tristeza, entorpecimento e negação (Parkes, 1988; Franco, 2010; Franco \& Polido, 2014, Kovács, 2003; Jamison, 2010, Flexhaug \& Yazganoglu, 2008; Fukumitsu, 2013; Andriessen \& Krysinska, 2012; Cândido, 2011; Clark, 2007; Shneidman, 1985 e 1993).

Diversos fatores influenciam a reação de cada um a uma perda importante. O enlutado enfrenta a necessidade de entender a ausência da pessoa amada, a redefinição do próprio papel na família e a inexatidão do que se perde. O modelo de processo dual do luto (Stroebe \& Schut, 1999) se diferencia dos demais tanto para a compreensão do processo quanto para programas de intervenção e cuidados. Nesta abordagem 
o luto oscila constantemente entre dois estressores: a "orientação para a perda" e a "orientação para a restauração" (Parkes, 1998; Cândido, 2011; Mazorra, 2009). Com base nessa abordagem de alternância entre estes dois processos, espera-se que a pessoa encontre significados para a perda por suicídio e possa viver dialeticamente seu processo de luto.

Além de ter de lidar com a morte e suas repercussões, o enlutado deve aprender a lidar com a ausência. Desta pode vir o desejo de resgatar o vínculo com o morto ("orientação para a perda"). Concomitantemente, começa-se a buscar a restauração da vida. O suicídio pode não significar apenas matar a si mesmo: a morte autoinfligida é um ato humano que provoca o sofrimento nas pessoas que ficaram e vivenciaram seu impacto.

\section{Método}

A pesquisa foi aprovada pelo Comitê de Ética em Pesquisa com Seres Humanos, os princípios éticos de sigilo, privacidade, confidencialidade, não identificação dos dados do colaborador e liberdade de participação foram respeitados. Todos os depoentes assinaram Termo de Consentimento Livre e Esclarecido (TCLE) e receberam as informações sobre as etapas da pesquisa, e os cuidados éticos foram respeitados. Foi um estudo de natureza qualitativa e teve como participantes nove filhos de indivíduos que consumaram suicídio. O número de colaboradores não foi previamente definido e dependeu do interesse pela participação na pesquisa entre o período de 2011 a 2012. Os critérios de inclusão foram: ser filho da pessoa que se matou, ter mais de 18 anos e ter disponibilidade para compartilhar sua experiência. Não havia nenhum critério de exclusão a priori, a não ser não ter as condições referidas e se a pessoa não quisesse participar da pesquisa. Para evitar sofrimento adicional no processo da entrevista consideramos que deveria haver um prazo de dois anos entre o evento do suicídio e a participação na pesquisa. Com menos de dois anos a pessoa ainda poderia estar sob o impacto do choque e em sofrimento intenso e participar da entrevista poderia ser muito penoso. No entanto, cabe ressaltar que este tempo foi uma estimativa e, caso houvesse sofrimento intenso e a pessoa manifestasse o desejo de interromper a sua participação, a pesquisadora acataria o pedido.

A pesquisa foi divulgada na internete os interessados foram convidados diretamente pela pesquisadora ou por indicação de colegas de trabalho. Nesse contato com os colaboradores, a entrevista foi agendada e realizada individualmente e em local conveniente ao entrevistado. Cabe salientar que as entrevistas foram agendadas previamente, que os horários foram respeitados conforme a disponibilidade do entrevistado e que este teve a liberdade de participar e de se retirar da pesquisa se achasse conveniente. Na Tabela 1 estão os dados de cada entrevistado, idade de ocorrência do suicídio, método do suicídio e gênero parental.

\section{Procedimentos}

Cada entrevista, que durou cerca de três horas, foi gravada com a anuência do depoente e, depois, enviada por e-mail com a respectiva transcrição. Os colaboradores receberam também mensagem com a interpretação que a pesquisadora fez dos dados coletados. A entrevista para coleta do depoimento foi aberta tendo-se proposto a questão disparadora: "Compartilhe sua experiência de ser filho(a) de um pai ou mãe que se suicidou". A entrevista iniciou-se com a apresentação do objetivo da pesquisa e posteriormente ao iniciar o processo da coleta o participante pode se expressar livremente. Só houve intervenção, em forma de perguntas, quando se considerou necessário aprofundar algumas questões, explorar ou esclarecer o que foi dito.

TABELA 1

Resumo dos dados dos colaboradores (gênero, pessoa que se suicidou, idade quando o suicídio aconteceu e método do suicídio).

\begin{tabular}{|c|c|c|c|c|}
\hline Entrevistado & Gênero & $\begin{array}{c}\text { Idade do entrevistado à } \\
\text { época do suicídio }\end{array}$ & Genitor que se suicidou & Método do suicídio \\
\hline $\mathrm{C} 1$ & Masculino & 17 anos & Pai & Choque elétrico \\
\hline $\mathrm{C} 2$ & Feminino & 9 anos & Mãe & Corte na jugular \\
\hline $\mathrm{C} 3$ & Feminino & 24 anos & Pai & Enforcamento \\
\hline $\mathrm{C} 4$ & Masculino & 14 anos & Pai & Enforcamento \\
\hline $\mathrm{C} 5$ & Feminino & 15 anos & Mãe & Ingestão de medicamentos \\
\hline C6 & Feminino & 7 anos & Mãe & Jogou-se do edifício \\
\hline $\mathrm{C} 7$ & Masculino & $12 / 13$ anos & Mãe & Enforcamento \\
\hline $\mathrm{C} 8$ & Feminino & 15 dias & Pai & Arma de fogo \\
\hline C9 & Feminino & 3 anos e 6 meses & Mãe & Jogou-se do edifício \\
\hline
\end{tabular}


O conteúdo foi analisado pelo método fenomenológico proposto por Clark Moustakas (1994). Ressalta-se que, ao utilizar o método fenomenológico, não se buscava predição ou generalização a situações de luto que outros filhos pudessem experimentar. Os passos para análise apresentaram a seguinte sequência. A entrevista transcrita foi lida várias vezes, exercitando a epoché, procedimento fenomenológico em que no processo da análise, a pesquisadora suspendeu conceitos prévios. A análise dos depoimentos e a derivação das unidades de significado foram feitas a partir da leitura das entrevistas e o agrupamento dos temas individuais. Posteriormente, foram agrupados em um arquivo todos os temas que se repetiram, compondo assim os principais temas de todos os entrevistados.

Os temas mais presentes foram organizados em sequência e em ordem crescente, compondo as 14 unidades de significado do processo de luto de filhos de quem se suicidou: a ausência presente e a presença ausente; a morte interdita e o empecilho do estigma do suicídio; o enfrentamento da morte violenta e escancarada - entre a tensão e o relaxamento; culpa e autoacusações; não é o fato que traumatiza, mas o processo como um todo: o estresse antes e depois do suicídio; o ilustre desconhecido: quem foi você, mãe/ pai? Existe uma parte sua em mim ou uma parte minha em você?; se meu pai/mãe se matou, eu também me matarei? Medos e transmissão psíquica transgeracional; a intensidade dos sentimentos e o estranho alívio; as lembranças vividas, as histórias contadas e as vivências emprestadas; poderia ser totalmente diferente: as especulações sobre a vida que não vivi; os sobreviventes que se unem e o interesse pela história de sobreviventes; manejos do processo de luto: ajudar outros, estudar, isolar-se, fazer psicoterapia, ser evangélica e escolher a profissão: psicólogo(a), historiador e arquiteta; o calar quando o falar seria importante; algo mudou depois do suicídio: as transformações na vida.

Considerou-se como estruturas universais as que descreveram sentimentos e pensamentos relacionados ao processo de luto por suicídio e a partir dessa organização, as unidades de significados foram determinadas. Apresentamos a seguir as unidades de significado acompanhadas de alguns dos depoimentos dos colaboradores.

\section{Ausência presente e presença ausente}

Esta unidade de significado versa sobre a ausência que se torna presente quando da morte de uma pessoa amada. Alguns dos entrevistados relataram que os genitores deram sinais de falta de sentido, isolavam-se, sofriam de transtornos mentais, fizeram tentativas prévias de suicídio e, por esta razão eram vistos como ausentes embora estivessem vivos. Foi o que ocorreu com o entrevistado $\mathrm{C} 4$, que conviveu com a doença psiquiátrica do pai, que de certa forma não estava presente no convívio com o filho, configurando um "esgotamento da família", nas palavras do colaborador. Há de se considerar que no luto por suicídio, aquele que se matou poderá ocupar no enlutado sobrevivente, um lugar de presença, mesmo após sua morte, por meio das lembranças e pelo sentimento de culpa, ou seja, a presença da pessoa que se suicidou permanece constantemente nas lembranças de momentos vividos. Nos casos de ausência presente, ressaltamos que muitos dos entrevistados afirmaram que, embora seus genitores fossem vivos, a ausência já acontecia em virtude do adoecimento de seus pais que não permitia o sentimento de que os filhos estavam sendo acompanhados em suas vidas.

\section{A morte interdita e o empecilho do estigma do suicídio}

Houve relatos de filhos que os pais nunca deram sinais de que poderiam se matar. Foi o caso do entrevistado $\mathrm{C} 7$, que indicou a impossibilidade de se despedir da mãe, que "fez uma viagem e não deu tempo de arrumar as malas".

Tudo parece fugir ao controle quando um suicídio acontece. A falta de informação acerca do que acontecia com a pessoa no momento em que se matou parece ser um dos aspectos que trazem maior sofrimento ao sobrevivente. A sensação de morrer juntamente com a pessoa que se suicidou pode levar à dificuldade de lidar com a sensação de impotência, acusações e culpa. O entrevistado $\mathrm{C} 7$ tinha 12 anos quando a mãe se enforcou no banheiro de casa e ouviu palavras de pessoas sem o devido cuidado. Compartilhou recordações que evidenciaram o estigma que acompanha o suicídio: cochichos, olhares, a possibilidade de sua mãe ter se matado por ser ele uma "criança levada". Apesar de a acusação não ter tido sentido para ele, a possibilidade de ter sido ele uma das motivações para o suicídio parece ter permanecido: "o problema foi o fato de eu ser levado. Então, a culpa é quando chegou em mim esse boato - não sei nem se é verdade".

No que diz respeito ao suicídio, considera-se que a morte repentina e inesperada pode provocar reações intensas, que variam entre a raiva e a necessidade de isolamento social. A intensidade das emoções são identificadas nos relatos dos enlutados sobre suas vivências de culpa, raiva, vergonha e dúvidas sobre o controle da própria vida (Mazorra, Franco, \& Tinoco, 2002; Fukumitsu, 2013; Andriessen \& Krysinska, 2012; Cândido, 2011; Clark, 2007) 


\section{$O$ enfrentamento da morte violenta e escancarada - entre a tensão e o relaxamento}

Alguns dos depoimentos remeteram ao choque sentido ao enfrentar o suicídio. Por tratar-se de morte violenta, o tema incluiu a metáfora utilizada pelo entrevistado C4 - "entre a tensão e o relaxamento" -, que bem representou os paradoxos no enfrentamento e superação dos enlutados de quem consumou suicídio.

É preciso refletir sobre a maneira de se oferecer amparo a uma pessoa que vivenciou o suicídio de um ente querido, principalmente quando encontrou o corpo, como foi o caso da entrevistada $\mathrm{C} 2$, que encontrou sua mãe desfalecida no banheiro com a veia jugular cortada. Com a compreensão de que a violência do evento pode ser impactante, os enlutados sobreviventes mencionaram que se sentiram anestesiados, em choque e manifestam interesse nas histórias de outros enlutados, como relatou o entrevistado $\mathrm{C} 1$ "Eu adoro assistir [a] documentários de sobrevivente do Shoah, do Holocausto, ou de outros genocídios, ou acidentes, ou tragédias". É necessário o acolhimento do enlutado por suicídio, que vive este impacto, respeitando a singularidade e as limitações de cada um. A tensão e o relaxamento são duas polaridades que compõem o processo de luto por suicídio, a tensão antes e durante o processo e o relaxamento quando o ato é consumado.

Para o enlutado o acontecimento principal passa a ser sua história com suas perdas, bem como a maneira como lidará com suas feridas existenciais. O suicídio é um evento que demanda a busca e necessidade prementes de reconstruir novos sentidos para que a pessoa continue sua vida, apesar da morte trágica e este é exatamente o ponto em que se encontra o paradoxo da existência, pois a partir do momento em que concebe a finitude do ente amado, percebe também as experiências que restaram da relação com quem se matou.

\section{Os sobreviventes que se unem e o interesse pela história de sobreviventes}

Choque, sensação de anestesia e o interesse pela história de outros sobreviventes parecem estar intrinsecamente em convergência, pois, com o impacto, o enlutado parece precisar de outras referências. Pela identificação com sobreviventes do Holocausto, o entrevistado $\mathrm{C} 1$ lidou mais facilmente com o próprio sofrimento. Os depoimentos dos filhos enlutados expuseram que, ao perder um dos genitores, viveram o luto e compartilharam a sensação de estarem perto do caos ou em crise. Nos dois casos, contempla-se a sobrecarga das pessoas para que possam se restabelecer com seus próprios recursos.
Deve-se realçar que os termos sobrecarga, recursos e reconciliação são ensinamentos de Franco (2002, p. 34) que afirma:

Se o luto por causa repentina ou violenta coloca o enlutado na condição de risco para desenvolver luto complicado, esta condição da nossa sociedade impõe a necessidade de um olhar mais cuidadoso para essas pessoas.

A sobrecarga é maior para o primeiro a encontrar o corpo da pessoa querida, como aconteceu com o entrevistado C7, que viu a mãe enforcada no banheiro de casa: "Quando a porta abriu, minha mãe estava enrolada em um fio de ferro de passar roupa, enforcada, morta. Ela só desceu para o chão por causa da extensão do corpo". A imagem do corpo morto e da morte personificada na pessoa amada impregna na mente e, por mais que o enlutado tente se afastar dessa visão, não consegue.

Apesar de perceber que a mãe estava triste, a entrevistada $\mathrm{C} 2$ viveu o sobressalto da experiência do suicídio, iniciando um percurso no qual teve, precocemente, de ser responsável para assumir não somente a própria existência, mas também de arcar com as tarefas antes desempenhadas pela mãe, como cuidar da irmã mais nova, do pai e das atividades de casa. O dever de deixar a mãe mais feliz no momento em que a percebia triste era sentido pela entrevistada C2: "Eu ficava tentando animá-la de algum jeito".

\section{O ilustre desconhecido: quem foi você, mãe/pai? Existe uma parte sua em mim ou uma parte minha em você?}

Embora se sentissem responsáveis pelos sentimentos dos genitores, alguns dos entrevistados não os conheciam. Esse fato pode ser visto como intercorrência da morte repentina que privou os enlutados do acompanhamento dos pais ao longo da vida, o que está relacionado com essa unidade de significado, que apresenta a energia empregada para conhecer os pais e que os filhos enlutados sofreram isso ainda crianças. Um dos caminhos foi investigar os gostos dos pais, como fez a entrevistada C9, que buscou as notas e as matérias que a mãe gostava e aquelas de que não gostava nos arquivos da faculdade de arquitetura, curso que foi trancado quando a mãe se descobriu grávida dela e que a entrevistada C9 frequentava à época da entrevista. A depoente buscou vários pontos de semelhança com sua mãe, traços físicos, de personalidade como se pode ver na sua fala "Eu sei que ela chorava muito e eu, quando estava deprimida, chorava demais". Destacou seu 
gosto pela arquitetura, pistas que pudessem confirmar que era parecida com sua mãe e que, portanto, teria assegurado um pouco de sua mãe em sua história. A unidade de significado em questão aponta a necessidade de o enlutado ter conhecido um pouco mais sobre o mundo daquele que se matou.

\section{Se meu pai/mãe se matou, eu também me matarei? Medos e transmissão psíquica transgeracional}

Esta unidade de significado abrange a reflexão sobre a transmissão psíquica transgeracional, também conhecida como contexto familiar suicidogênico (Krüger \& Werlang, 2010). O depoimento do entrevistado C1 ilustra o tema:

O que me vem é que eu sempre tive medo de seguir os passos do meu pai. Eu associo muito o suicídio dele à solidão. E eu tenho me isolado muito ultimamente, de um ano para cá. ... Se o raio já caiu uma vez, vai cair de novo, sim. E no mesmo lugar, ou no lugar onde eu estiver. Eu só estou te falando de crenças, das mais profundas, como se tivesse sido gravado, como se tivesse sido marcado com ferro vermelho.

$\mathrm{O}$ entrevistado $\mathrm{C} 1$ compartilhou o receio de se matar e a angústia afirmando ter "plena consciência do dia que ultrapassaria o pai", morto aos 40 anos, em longevidade. A fantasia do efeito imitativo do suicídio parece emergir não somente nos filhos, mas também em outros familiares. Porém, apesar de esse medo do efeito imitativo ser percebido em quem vive o luto pelo suicídio, é injusto julgar os enlutados como herdeiros do suicídio. Como Fox e Roldan (2009) mencionam: "Ninguém tem o direito de sugerir que o filho ou filha da pessoa que se suicidou fará o mesmo e seguirá os mesmos passos de seus pais" (p. 44).

O sentido da morte por suicídio pode nunca ser compreendido e a memória não é mais o registro das experiências que o enlutado teve com a pessoa que se matou. Nota-se, pois, que, sem respostas às perguntas, alguns enlutados talvez não consigam dar destino às próprias aflições.

\section{As lembranças vividas, as histórias contadas e as vivências emprestadas}

Essa unidade de sentido expressa a necessidade de o enlutado reconstruir ou construir, uma história vívida com aquele que se matou para tentar se conectar com a própria história. A entrevistada $\mathrm{C} 8$ compartilhou a falta de registro dessas vivências. Ainda bebê, aos 15 dias de vida, vivenciou a primeira morte: a do pai, que atirou na própria cabeça. O que foi possível vivenciar enquanto bebê? A resposta de $\mathrm{C} 8$ aparece em forma de um não saber:

Então, tudo o que eu sei é pela minha mãe. $O$ luto não senti, não tive isso, acho que eu não tive isso. Eu sempre falo que eu perdi uma pessoa que eu nunca tive, mas, às vezes, a gente não sabe o porque exatamente ele se matou.

Para alguns enlutados pelo suicídio, a morte trouxe marcas, e algumas das vivências descritas apontaram padrões disfuncionais preexistentes no contexto familiar e quadros psiquiátricos, como transtorno bipolar e depressão. Famílias inseridas no contexto da crise suicida precisam de auxílio e amparo para que possam ressignificar comportamentos autodestrutivos. Nesse sentido, precisam se reconstruir como um sistema de apoio e proteção como ensinam Krüger e Werlang (2010).

\section{Não é o fato que traumatiza, mas o processo como um todo: $o$ estresse antes e depois do suicídio}

A mãe da entrevistada $\mathrm{C} 2$ se matou depois que "fez o jantar normal. Dia normal. Ela serviu o jantar para a gente, a gente tomou banho, ela serviu o jantar. Entrou no banheiro e não saiu mais".

Habitualmente, o ser humano acorda e imagina que viverá um "dia normal”. Crença necessária, porém, utópica, uma vez que qualquer dia pode ser aquele em que os rumos da vida de qualquer pessoa podem mudar. No caso de C2, no dia do suicídio iniciou-se seu processo de luto no qual teve de aprender a lidar com o sofrimento e ressignificar a própria vida.

A unidade de significado apresenta o estresse na família da pessoa que morreu pelo suicídio e que, muitas vezes, é acompanhado pelo adoecimento no contexto familiar ou pelo fato de um membro da família sofrer de doença mental e por haver ameaça constante com as tentativas de suicídio recorrentes (Clark, 2001; Krüger \& Werlang, 2010).

Apesar de as pessoas compreenderem que a escolha pelo suicídio foi da pessoa que já manifestava estresse, a culpa e a autoacusação estiveram presentes nos depoimentos dos enlutados. O suicídio é a escolha única e exclusiva da pessoa que se matou. Essa opção pode decorrer de um processo de uma vida de estresse advindo de frustrações. O estresse também é provocado pela maneira de a pessoa lidar com conflitos e crises existenciais e grande parte desse manejo consiste em aprender novas maneiras de tolerar existencialmente as adversidades. O pensamento rígido faz com que 
a solução para os problemas funcione pelo viés da ambivalência entre "tudo" ou "nada"; "certo" ou "errado", em situações de adversidades. A pessoa não consegue lidar com as dificuldades e acaba apresentando o tunnel vision fazendo com que a morte seja vista como a única forma de lidar com o sofrimento existencial como aponta Shneidman (1993). Se antes do suicídio, o enlutado apresentava dificuldades para lidar com adversidades e frustrações, durante e depois da morte do ente querido, há de se pensar que poderá se acentuar o estresse, devido ao impacto da morte violenta e inesperada.

\section{Culpa e autoacusações}

A culpa é um dos fatores que tornam o luto por suicídio penoso em virtude de ser morte impactante e pelo estigma que carrega. O suicídio desafia a potência da família, pois desperta o pensamento de que algo diferente poderia ter sido feito ou que o sobrevivente deveria ter visto ou previsto, tido cuidado para evitar a morte. Os depoimentos evidenciaram a dificuldade de se desvencilhar da culpa e não se deixar dominar pela autoacusação. A culpa é um sentimento que dificulta que o enlutado se reorganize, pois, a sua energia psíquica está sempre voltada para lidar com as consequências emocionais decorrentes da ideia fantasiosa de que a situação poderia ser totalmente diferente do desfecho do suicídio. É maneira de o enlutado se reorganizar na situação desconfortável. Caso a situação não tenha sentido, a culpa e as autoacusações são explicações plausíveis cuja energia é direcionada para o próprio indivíduo.

\section{A intensidade dos sentimentos e o estranho alívio}

A raiva parece emergir proporcionalmente aos sentimentos de culpa, impotência, frustração e rejeição. $\mathrm{O}$ entrevistado $\mathrm{C} 1$ compartilha a intensidade dos sentimentos e o estranho alívio com a morte do pai, por choque elétrico, e que expressou o sofrimento provocado pelas várias brigas entre pai e mãe, irmão e mãe, tentativas prévias de suicídio e o transtorno bipolar, dizendo sentir muita "... raiva, culpa, a vergonha e vergonha de ter raiva. É como se fosse uma ferida num lugar tão difícil de curar. É como se tivesse que fazer uma cirurgia do cerebelo, sei lá, num lugar bem inalcançável. É algo muito profundo”. No entanto, a intensidade dos sentimentos em relação a quem já morreu parece ser atordoante, pois embora pareça desrespeito para com quem se matou, os enlutados já viveram o rompimento do vínculo antes de o suicídio acontecer e, por esse motivo, a morte da pessoa foi experimentada com alívio.

\section{Poderia ser totalmente diferente: as especulações sobre a vida que não vivi}

Essa unidade de significado expressa a mágoa por não ter sido poupado, por ter de se refazer do caos instalado antes, durante e depois do suicídio. O suicídio é considerado uma transgressão pela sociedade, pois afronta o instinto de sobrevivência. O estigma pode ser mantido quando a mídia desrespeita a recomendação de evitar sensacionalismo, imagens, detalhamento das causas ou explicitação de que foi suicídio. No suicídio, a pessoa que morre e a família não têm assegurada a privacidade: a morte acaba pertencendo também aos espectadores, com julgamentos indevidos. É como afirma a entrevistada C3 sobre quando o pai se enforcou na casa de materiais perto de onde moravam, mencionando que pelo suicídio ter acontecido na cidade do interior, "todo mundo falando o que quer, o que acha, o que pode, o que não pode, o que deve, o que não deve, sem saber se tem alguém por perto, sem respeitar nem nada".

Os familiares de quem se mata podem se sentir julgados: ouvem que não foram capazes de perceber os sinais de que a pessoa se mataria, que são doentes ou loucos por causa do suicídio. O sobrevivente sente vergonha, pois além dos remorsos enfrenta o preconceito.

O suicídio é tabu, uma morte que carrega estigma. Os sobreviventes compartilharam a vergonha de apontar a causa da morte e preferem dizer que a pessoa sofreu um acidente de carro ou que morreu por descuido a dizer que a morte aconteceu pelo suicídio.

\section{O calar quando o falar seria importante}

Há um ponto a ser ressaltado: para alguns enlutados, o verbo "cometer" associado ao suicídio pode acentuar a vergonha. Segundo Smith (2013, p. 23), quando alguém "comete" algo, comete pecado ou crime. Mas nem pecado ou crime: o suicídio revela o desespero humano. O estigma do suicídio é percebido no silêncio e no isolamento do sobrevivente para evitar constrangimentos, como assinala o depoimento da entrevistada C9, que tinha três anos quando a mãe se matou jogando-se do edifício: "Então, é meio complicado. Porque eu não tenho informação nenhuma. Não se fala. Não se fala nem entre eles [família]. A questão não é esconder de mim, a questão $e ́$ [que] não se fala".

Acreditamos que um dos motivos para que o suicídio siga estigmatizado seja o seu aspecto de morte escancarada: que invade a vida das pessoas pela violência e pela banalização, deixando os sobreviventes vulneráveis, como aponta Kovács (2003). 


\section{Novas formas de vida podem ser planejadas, após uma paralisação que o suicídio provoca}

O suicídio causa tanto impacto que não fica claro o que de fato se perde. A exatidão é abalada e, assim como a relação com aquele que se suicidou se modifica, a pessoa enlutada também muda. Apesar de alguns depoentes manifestarem resiliência, transformações e um modo muito peculiar de prosseguir, a maioria dos enlutados confirmou que a vida não volta a ser como antes desse evento tão agressivo: tudo parece rápido, abrupto, e o desconhecido leva a pessoa a não saber mais como viver ou, como tratado neste estudo, sobreviver. Nesse sentido, como dito anteriormente, neste estudo, a pessoa que sofreu o impacto do suicídio foi reconhecida como sobrevivente, seja familiar, amigo ou até a pessoa que testemunhou a morte violenta.

Quando o suicídio da pessoa querida acontece, a morte é vivida de maneira consciente. Por isso, sua elaboração é possível e necessária para enfrentar o desequilíbrio, a desorganização do sistema familiar, a dor solitária, o processo longo e sofrido e a busca constante da força para continuar a viver. Como é para uma pessoa seguir vivendo com uma lembrança tão trágica? Sendo o suicídio um evento repentino e carregado de estigma, que marca o ser humano pela violência e rapidez e que foi a escolha de quem se mata, o enlutado precisa desenvolver habilidades para lidar com a nova realidade. Encontrar novos rumos na vida não significa desonrar a pessoa que se matou, por isso o processo de luto é uma tarefa árdua e gradual. Franco (2002) afirma que a reconciliação “... é mais expressiva daquilo que ocorre, à medida que o enlutado integra essa nova realidade de se mover ao longo da vida sem a presença física da pessoa que morreu" (p. 27).

Quem mata quem quando acontece o suicídio? A sensação do enlutado parece a de morrer juntamente com aquele que se foi. Apesar da intensidade do sofrimento, os entrevistados viveram o luto e direcionaram as energias para a busca de sentido. Como relata C1: “Apesar de ter feito 15 anos, estou há 15 anos em terapia. Eu toco frequentemente no assunto do meu pai, quando falo no assunto, falo do suicídio, falo da minha relação com ele, falo da culpa".

\section{Ajudar outros, estudar, isolar-se, fazer psicoterapia, ser evangélica e escolher a profissão: psicólogo(a), historiador e arquiteta}

Os entrevistados relataram precisar de fortalecimento e ensinaram diversos manejos para lidar com o luto: ajudando os outros, isolando-se quando se sentiram ameaçados pelos julgamentos alheios, fazendo psicoterapia, escolhendo determinada profissão ou religião. A melhor maneira de acolher o sofrimento provocado pelo suicídio deve derivar do próprio enlutado que tem o direito de viver o processo de luto a seu modo e conforme o tempo que for necessário.

\section{Considerações Finais}

Neste estudo, surgiram reflexões sobre a quem pertence a vida, se existem culpados ou responsáveis pelo suicídio. Alguns entrevistados assumiram responsabilidade pelo que viveram, outros aceitaram a tarefa de cuidar também de outros enlutados. Os sentimentos são variados e têm intensidades diferentes. A pessoa que se mata pode não deixar aviso prévio ou pedir permissão para o ato. Estar em luto significa também educar outros para compreender os significados desse tipo específico de morte. Educação para a morte é o que Kovács (2003) propõe em seu estudo ao convidar a pensar no sofrimento e em aspectos da vida como formas de acolher a vida sem a presença da pessoa querida.

Os benefícios desta pesquisa se mostram no acolhimento e na escuta recebidos pelos enlutados ao compartilhar suas vivências. Cabe ressaltar que em levantamento bibliográfico observamos poucas pesquisas sobre o tema como apresentamos na introdução teórica deste artigo, então este artigo apresenta a sua importância e se espera que outros estudos possam acontecer, pois os índices de suicídio têm aumentado de forma significativa como mostram as estatísticas, e também cresce o número de enlutados que precisam ter seu cuidado expandido.

Viver o suicídio de uma pessoa querida causa grandes transformações. O luto pelo suicídio pode criar um hiato se houver falta de cuidado e de amor, um espaço de sofrimento psíquico e contempla “... as consequências da morte do outro; enfrentar as perguntas sem respostas e explicações sem comprovações; lidar com especulações sobre a vida daquele que se matou" (Fukumitsu, 2013, p. 66). Como apontamos não é o fato que traumatiza, mas o processo como um todo e a intensidade das emoções, que se originam quando um suicídio acontece. "Por que a pessoa se matou?", talvez seja a questão mais frequente na experiência de quem vive o luto pelo suicídio. O suicídio é sempre uma situação de grande impacto que muitos afirmam que gostariam que não tivesse acontecido.

A nosso ver, nunca saberemos as reais motivações de a pessoa ter se aniquilado, pois a verdade se foi juntamente com a pessoa que se matou. Os enlutados por suicídio tentam, ao buscar explicações e sentidos para o que aconteceu, estabelecer relações da morte 
com o adoecimento, outros vinculam o suicídio ao desespero. Há depoimentos que mostram a dificuldade de compreensão do autoextermínio, restando mais perguntas do que respostas. $\mathrm{O}$ choque da situação traumática provoca nos enlutados sobreviventes sentimentos de falta de hospitalidade, de estranheza com uma diversidade de sentimentos, tais como, culpa, choque, autoacusação, raiva, busca por lembranças, vergonha, isolamento, rejeição, falta de sentido e necessidade de explicações, configurando as mais importantes sequelas da vivência da morte por suicídio.

O estudo apresentou também histórias relacionadas ao suicídio nas quais houve reconciliação e evidenciou que o início de uma nova história pode ser demarcado a partir do final da vida de outra pessoa. Os entrevistados compartilharam o impacto do suicídio, a busca do sentido de viver apesar do sofrimento e os caminhos pelos quais puderam transformar vergonha em permissão, culpa em compaixão, saudade em apropriação das vivências, dor em amor e sofrimento em altruísmo.

Os enlutados por suicídio podem ressignificar as sequelas da morte escancarada e interdita. São, portanto, compreendidos como sobreviventes e transcendem a possibilidade de morrer juntamente com aquele que se suicidou. Acredita-se que pessoas que tiveram a experiência de ter alguém que se matou, aprendem a não se entregar ao sentimento de abandono e desamparo provocados pelas reverberações do suicídio. Precisam aprender a se cuidar e a receber cuidados de outras pessoas.

Este estudo trouxe os depoimentos de pessoas que viveram o suicídio de seus pais, organizados em unidades de significado. Sabemos que são reflexões iniciais sobre um tema tão amplo como o luto por suicídio. Outros estudos poderão ampliar o escopo para a compreensão do atendimento de pessoas que têm a experiência de sofrer o impacto do suicídio de um ente amado. Este artigo apontou vulnerabilidades e potencialidades como foco importante para pesquisas brasileiras que contribuam para o atendimento do luto por suicídio. Profissionais da saúde devem ampliar as reflexões sobre recursos e estratégias de reconciliação e de enfrentamento utilizados para acolhimento ao luto pela morte autoinfligida. Cabe também salientar sobre a importância de se incluir o tema do suicídio na formação de psicólogos e de profissionais de saúde que trabalharão em instituições a fim de se propiciar o atendimento a pessoas com ideação ou tentativa de suicídio e cuidados para os familiares enlutados por suicídio. No Brasil, o termo posvenção ainda não é conhecido, precisa ser mais divulgado para que se possam criar serviços de cuidados as pessoas que vivem tão profundo sofrimento ao perder pessoas queridas por suicídio.

\section{Referências}

Alvarez, A. (1999). O Deus Selvagem: um estudo do suicídio. São Paulo: Companhia das Letras.

Andriessen, K. \& Krysinska, K. (2012). Essential questions on suicide bereavement and postvention. In Int J Environ Res Public Health, 9(1), 24-32. http://dx.doi.org/10.3390/ijerph9010024

Bertolote, J. M. (2012). Suicídio e sua prevenção. São Paulo: Unesp.

Botega, N. J., Werlang, B. S. G., Cais, C. F. da S., \& Macedo, M. M. K. (2006, set;-dez.). Prevenção do comportamento suicida. Psico, 37(3), 213-220.

Cândido, A. M. (2011). O enlutamento por suicídio: elementos de compreensão na clínica da perda. [Dissertação de Mestrado], Universidade de Brasília, Brasília.

Cassorla, R. M. S. (1991). Do suicídio: estudos brasileiros. Campinas: Papirus.

Clark, S. (2001). Bereavement after suicide: How far have we come and where do we go from here? Hogrefe e Huber Publishers - crisis, Austrália, 22(3), 102-108.

Clark, S. (2007). Depois do suicídio: apoio às pessoas em luto. Tradução Marcello Borges. São Paulo: Gaia.

Flexhaug, M. \& Yazganoglu, E. (2008). Alberta Takes Action on Suicide: Best and Promising Practices in Suicide Bereavement Support Services: A Review of the Literature. In: Prevention, Alberta Health Services-Alberta Mental Health Board Suicide. Canadá: Alberta Health Services.

Franco, M. H. P. (2002). Estudos avançados sobre o luto. Campinas, Livro Pleno.

Franco, M. H. P. (2010). Formação e rompimento de vínculos: o dilema das perdas na atualidade. São Paulo: Summus Editorial.

Franco, M. H. P. \& Polido, K. K. (2014). Atendimento psicoterapêutico no luto. São Paulo: Zagodoni.

Fox, J. Z. \& Roldan, M. (2009). Voices of strength: sons and daughters of suicide speak out. Far Hills, NJ: New Horizon. Fukumitsu, K. O. (2012). Suicídio e Gestalt-terapia. São Paulo: Digital Publish e Print. 
Fukumitsu, K. O. O processo de luto do filho da pessoa que cometeu suicídio. 2013. 237 f. [Tese de Doutorado], Instituto de Psicologia, Universidade de São Paulo, São Paulo, 2013.

Fukumitsu, K. O. (2013). Suicídio e luto: histórias de filhos sobreviventes. São Paulo: Digital Publish e Print.

Jamison, K. R. (2010). Quando a noite cai: entendendo a depressão e o suicídio (2 2 ed.). Rio de Janeiro: Gryphus.

Kovács, M. J. (Ed.). (1992). Morte e desenvolvimento humano. São Paulo: Casa do Psicólogo.

Kovács, M. J. (2003). Educação para a morte: temas e reflexões. São Paulo: Casa do Psicólogo.

Kovács, M. J. (2007). Perdas e o processo de luto. In D. Incontri \& F. S. Santos (Eds.). A arte de morrer. Visões plurais (pp. 217-238). São Paulo: Comenius.

Krüger, L. L. \& Werlang, B. S. G. (2010). A dinâmica familiar no contexto da crise suicida. Psico-USF, 15(1), 59-70. http://dx.doi.org/10.1590/S1413-82712010000100007

Mazorra, L. (2009). A construção de significado atribuído à morte de um ente querido e o processo de luto. [Tese de Doutorado], Instituto de Psicologia, Pontifícia Universidade Católica de São Paulo, São Paulo.

Mazorra, L., Franco, M. H. P., \& Tinoco, V. (2002). Fatores de Risco para luto complicado numa população brasileira. In M. H. O. Franco (Ed.). Estudos avançados sobre o luto. Campinas: Livro Pleno.

Moustakas, C. (1994). Phenomenological research methods. Thousand Oaks: Sage Publications.

Parkes, C. M. (1998). Luto. São Paulo: Summus.

Rappaport, N. (2009). In her Wake: A child psychiatrist explores the mystery of her mother's suicide. New York: Basic Books.

Shneidman, E. (1973). Deaths of man. New York: Quadrangle.

Shneidman, E. (1985). Definition of suicide. Michigan: Wiley.

Shneidman, E. (1993). Suicide as Psychache: A clinical approach to self-destructive behavior. London: Jason Aronson.

Shneidman, E. (1996). The suicidal mind. Oxford: Oxford University Press.

Shneidman, E. (2001). Compreending suicide: Landmarks in 20th-Century Suicidology. Washington: American Psychological Association. http://dx.doi.org/10.1037/10406-000

Smith, T. (2013). The unique grief of suicide: questions e hope. Bloomington: iUniverse.

Stroebe, M. S., e Schut, H. (1999). The dual process model of coping with bereavement: Rationale and description. Death Studies, 23, 197-224. http://dx.doi.org/10.1080/074811899201046

Waiselfisz, J. J. (2014). Prévia do mapa da violência 2014. Os jovens do Brasil, São Paulo: Ministério da Justiça. Recuperado em 30 set. 2014, de: http://www.mapadaviolencia.org.br/pdf2014/Previa_mapaviolencia2014.pdf

\footnotetext{
Autores: Desenvolvimento Humano do Instituto de Psicologia da USP. da Aprendizagem, do Desenvolvimento e da Personalidade

Endereço para correspondência:

Rua Tabor, 647, Torre G, ap. 72 - Bairro Ipiranga

04202-021 - São Paulo, SP, Brasil

Recebido em: 23.12 .2014

Aceito em: 25.11.2015
}

Karina Okajima Fukumitsu - Doutor, Universidade de São Paulo - Pós-doutoranda do Programa de Pós-Graduação em Psicologia Escolar e

Maria Júlia Kovács - Doutor, Universidade de São Paulo - Professor Livre Docente do Instituto de Psicologia da USP, Departamento: Psicologia 